\title{
A MODERNIDADE TÉCNICA
}

\section{Franz Josef Brüseke}

O fato de que a modernidade, como época histórica, nasce com a ciência e a técnica moderna, mostra hoje toda a sua virulência. Podemos até dizer que essa modernidade é tão penetrada pela "técnica" que ela pode ser denominada e caracterizada como "modernidade técnica". Todavia, o surgimento da modernidade técnica não inviabiliza vieses interpretativos que apontam para as especificidades da cultura política e social da modernidade, apesar de identificarem e confundirem freqüentemente a história da Europa e da América do Norte com a história universal. Também trabalhos que destacam caminhos específicos na direção da modernidade, entre eles o caminho brasileiro, permanecem com seu grande valor explicativo. Pois essas interpretações confrontam-se mais cedo ou mais tarde com um debate sobre "valores" políticos e culturais, que não conseguem se livrar de um dilema: ou recorrem aos parâmetros europeus para nos dizer o que é moderno e o que não é ou, tentando evitar um olhar "eurocêntrico", perdem-se num relativismo sociocultural que inviabiliza, finalmente, o conceito universal da modernidade. A fala de uma variedade de modernidades não consegue nos dizer o que essas modernidades têm em comum. Propomos o conceito da modernidade técnica para evidenciar o que nos parece essencial, isto é, seu caráter técnico, e falamos sobre a emergência desta modernidade para evocar, por um lado, seu advento processual e histórico, e, por outro, seu alto grau de instabilidade e imprevisibilidade.

\section{A autodefinição da modernidade}

É prudente não julgar as pessoas na base daquilo que acham que são. Nem sempre aquele que se autopercebe como sendo justo o é de fato. Ainda menos devemos julgar toda uma época históri- 
ca partindo da sua autodefinição. Liberdade, igualdade, emancipação do homem da sua menoridade por meio do uso da razão, progresso social e econômico, superação da fome e das doenças, paz ao invés da guerra, e também em versão mais recente: individualidade, autenticidade e autorealização, reconhecimento da diferença, comunicação, participação. É um belo catálogo de promessas da modernidade européia que tem a sua versão comunista, afinal, também européia, enfatizando a igualdade em detrimento da liberdade, a satisfação das necessidades básicas em detrimento das necessidades culturais e espirituais, vangloriando a verdade absoluta em detrimento da relatividade individual e, assim, coroando as promessas modernas com uma escatologia histórica. Não é expressão de um espírito vingativo, incluir o comunismo soviético, chinês, cambodjano, vietnamita etc. no projeto da modernidade que, nesta versão, como sabemos, são projetos inacabados. É oportuno incluir estes fracassos de uma grandiosa tentativa de modernização socioeconômica na conceitualização daquilo a que chamamos moderno para nos sensibilizarmos em relação àquilo que une, mesmo que de forma paradoxal, estes países aos países ocidentais. As elites revolucionárias apostaram tanto quanto as elites burguesas e empresariais do ocidente no desenvolvimento técnico como a conditio sine qua non de qualquer avanço social. Os capitalistas de Manchester e posteriormente de Chicago não precisavam ler Marx para saber da centralidade do progresso técnico no processo de aumento da produtividade do trabalho e os ideólogos do welfarestate sempre souberam que só pode ser distribuído o que antes for produzido.

\section{A triade modernizante}

O nacional-socialismo alemão, outro projeto da modernidade pouco identificado pelos teóricos como tal, completa a tríade modernizante no século XX, composto pelo paradigma comunista, nacional-socialista e democrático ou, para simplificar ainda mais, pelo modelo russo, alemão e americano. Hoje já estamos à caminho de esquecer que estes modelos eram altamente competitivos entre si e que era difícil prever que o modelo americano venceria a disputa. O projeto nacional-socialista era deficiente em sua autolegitimação política, era um modelo excludente a tal ponto que somente uma única população tinha chance de ser atendida por ele: os próprios alemães. Este modelo, no entanto, carregava elementos de legitimação coletivistas, comunitários e socialistas, que acabaram criando simpatias também em movimentos políticos fora da própria Alemanha. Além do fascismo italiano e espanhol, também o populismo latinoamericano carrega traços de ser um "sócio" menor e tímido deste projeto.

O projeto político excludente dos nacionalsocialistas foi lançado na Europa baseado em sua modernidade militar e em sua modernidade econômica. Mais de 55 milhões de pessoas tiveram de deixar a sua vida para conter essa onda modernizante que varria a Europa de Berlim até Moscou e o centro de Stalingrado, uma onda que com uma técnica militar temporariamente superior à dos aliados, conseguiu estender sua influência até o norte da África, e as costas do atlântico. Seis anos de guerra foram necessários para destruir militarmente o projeto nacional-socialista que, apesar de ter negado o lado cultural e político da modernidade, mostrou toda a sua força militar, administrativa, econômica, estratégica, isto é, todo o potencial da modernidade técnica.

A derrota do nacional-socialismo reduziu a tríade modernizante a uma constelação bipolar, opondo, de 1945 a 1989, o modelo ocidental ao modelo comunista. Este último tinha, diferentemente daquele dos nacional-socialistas, um discurso mais atraente, pois não excluía outras raças ou populações, pelo contrário, incluía-os. Militarmente forte, compartilhando o nível técnico das tropas americanas e ocidentais, este projeto conseguia driblar as suas deficiências econômicas na base da austeridade do consumo e da transferência forçada do mais-produto agrícola para o complexo industrial-militar, até entrar em colapso na década de 1980. Assim, o modelo alemão representava a modernidade técnica no setor militar e econômico, sem sua dimensão política e cultural, enquanto o modelo russo apresentava um projeto militar moderno, sem modernidade política, e 
com uma curiosa sustentação econômica na base de um projeto desenvolvimentista, tendo o Estado ao centro. Mais uma vez, não estava claro o fim da disputa entre o projeto ocidental e o soviético. Temporariamente era tão grande a incerteza dos americanos em relação ao fim da guerra fria que eles partiram para "guerras quentes", como na Coréia e no Vietnã, a fim de conter o avanço do comunismo em países recentemente libertados da tutela colonialista. Pois apesar do discurso classista do comunismo - que devido ao seu moralismo universalizante encontra adeptos singulares até hoje -, em razão de suas contradições econômicas e políticas internas houve uma ruptura em seu projeto original. Restou apenas o modelo americano, econômica, política e militarmente moderno, cujo discurso universalizante acompanha $\mathrm{o}$ processo da globalização do seu próprio projeto.

Quadro 1

Três tipos ideais da modernidade técnica

\begin{tabular}{|c|c|c|c|}
\hline & $\begin{array}{l}\text { NACIONAL-SOCIALISMO } \\
(\text { (MODELO ALEMÃO) }\end{array}$ & $\begin{array}{c}\text { COMUNISMO } \\
\text { (MODELO RUSSO) }\end{array}$ & $\begin{array}{c}\text { DEMOCRACIA } \\
\text { OCIDENTAL } \\
\text { (MODELO AMERICANO) }\end{array}$ \\
\hline $\begin{array}{l}\text { DisCuRso POLÍtICO } \\
\text { LEGITIMATÓRIO }\end{array}$ & $\begin{array}{l}\text { Racista: o povo } \\
\text { alemão }\end{array}$ & $\begin{array}{l}\text { Classista: todos } \\
\text { os operários e } \\
\text { camponeses }\end{array}$ & $\begin{array}{l}\text { Universalizante: } \\
\text { todos os homens }\end{array}$ \\
\hline $\begin{array}{l}\text { PRINCÍPIO } \\
\text { LEGITIMATÓRIO } \\
\text { PRIMEIRO }\end{array}$ & $\begin{array}{l}\text { Physis: } \\
\text { o culto das forças } \\
\text { originárias em } \\
\text { detrimento das } \\
\text { forças do bem e } \\
\text { do real }\end{array}$ & $\begin{array}{l}\text { Nomos: o culto } \\
\text { das forças do } \\
\text { bem em } \\
\text { detrimento das } \\
\text { forças do real } \\
\text { e das origens }\end{array}$ & $\begin{array}{l}\text { Logos: } \\
\text { o culto das } \\
\text { forças do real } \\
\text { em detrimento } \\
\text { das forças do } \\
\text { bem e das } \\
\text { origens }\end{array}$ \\
\hline DIMENSÕES MODERNAS & $\begin{array}{l}\text { Militar; econômica; } \\
\text { (com inclusão de } \\
\text { poucos elementos } \\
\text { escravistas e estati- } \\
\text { zantes); }\end{array}$ & $\begin{array}{l}\text { Militar; } \\
\text { econômica, } \\
\text { (com inclusão } \\
\text { de fortes ele- } \\
\text { mentos } \\
\text { escravistas; } \\
\text { fortemente } \\
\text { estatizante) }\end{array}$ & $\begin{array}{l}\text { Política; militar } \\
\text { econômica, (com } \\
\text { elementos } \\
\text { estatizantes } \\
\text { moderados; } \\
\text { estado de direito } \\
\text { forte); }\end{array}$ \\
\hline $\begin{array}{l}\text { DEFINIÇÃO DO } \\
\text { PROGRESSO }\end{array}$ & $\begin{array}{l}\text { Técnico; étnico- } \\
\text { culturalista }\end{array}$ & $\begin{array}{l}\text { Técnico; } \\
\text { classista- } \\
\text { internacionalista }\end{array}$ & $\begin{array}{l}\text { Técnico, } \\
\text { universalizante- } \\
\text { individualista }\end{array}$ \\
\hline $\begin{array}{l}\text { IDEALIZAÇÃO } \\
\text { (LEITIBILD) }\end{array}$ & $\begin{array}{l}\text { Do operário, } \\
\text { camponês e soldado } \\
\text { alemão }\end{array}$ & $\begin{array}{l}\text { Do operário e } \\
\text { camponês } \\
\text { comunista }\end{array}$ & $\begin{array}{l}\text { Do cidadão } \\
\text { profissional e } \\
\text { consumidor }\end{array}$ \\
\hline
\end{tabular}


Se procurarmos compreender a modernidade como algo essencialmente técnico, evitaremos uma discussão sem parâmetros sobre os ideais iluministas, em que uma boa idéia se opõe a outra. Difícil, embora não impossível, é contestar os paradigmas da modernidade com sua razão centrada no sujeito, sua racionalidade e cientificidade, seu clamor pela igualdade, liberdade e justiça, seu humanismo e sua moralidade universal, sua valorização do direito, da ordem e do progresso da humanidade. Pois estes paradigmas da modernidade representam um amálgama de resquícios da consciência moral cristã, de um individualismo nascente buscando segurança institucional e novas formas racionalizantes de se pensar o mundo, bem como o homem no mundo. No século XVIII, o progresso era entendido como algo que envolve as virtudes do homem, para não dizer mesmo a sua alma. Já no século XIX assistimos a uma "materialização" deste entendimento. Misteriosamente, agora os seres vivos tendem para a evolução de espécies mais aptas para o struggle for life, a organização biológica e social progride da sua forma mais simples para uma cada vez mais complexa. Do micróbio ao cérebro humano, da sociedade tribal primitiva à civilização inglesa e francesa: progresso por todos os lados!

De acordo com Max Weber (1981), os primeiros empresários capitalistas ainda não tinham idéia do que faziam, mas, movidos pelo desejo de garantir a salvação da própria alma, faziam com eficiência. Como efeito não intencionado, mobilizou a ascese intramundana e o trabalho profissional ininterrupto as forças produtivas do capitalismo, revelando agora frente ao olho analítico de um Karl Marx a sua essência. (Já que Weber reconhece a existência do espírito do capitalismo nos é permitido falar de sua essência.) Essa essência era técnica, era a técnica do trabalho desde a idade da pedra até a revolução industrial e a produção da mais-valia relativa. A novidade da análise socioeconômica de Marx não era ter mostrado o caráter imoral ou exploratório da sociedade contemporânea - a humanidade até então sempre havia se organizado em formas injustas e exploratórias - mas sim ter destacado o papel das forças produtivas no processo histórico. Estas forças pro- dutivas, quando envolvem o trabalho e a organização humana, também são técnicas. Acontece que Marx nos diz que a essência do capitalismo é técnica sem ao menos perguntar o que é a essência da técnica.

O surgimento da máquina exige, antes de sua materialização em equipamentos inorgânicos, a máquina no sentido restrito, sua invenção no plano organizacional (Mumford, 1966). Uma grandiosa máquina humana era responsável pela construção das pirâmides egípcias, mas integrava também alguns instrumentos de trabalho extremamente simples. O que caracteriza este tipo de técnica pré-moderna é seu alto nível finalístico, tirando a vontade de alcançar o seu único fim - qual seja, a construção de monumentos fúnebres para os faraós -, desaparece o seu meio técnico. Com a desorganização da máquina humana, as forças produtivas da época reduzem-se a algumas cordas, alavancas e roldanas.

\section{A perda do caráter finalístico da técnica}

A técnica sempre foi um meio usado pelo homem para alcançar determinados fins. A racionalidade de fins é tanto expressão de processos técnicos, como sua causa movens. Fora de um processo manipulatório, seja qual for a sua natureza, um instrumento de trabalho técnico é simplesmente ininteligível. Um serrote serve para serrar madeira, sem madeira e sem alguém que a serre, este serrote perde a sua finalidade. O caráter finalístico da técnica, a sua definição como um meio para se alcançar fins definidos pelo homem, é algo tão óbvio que parece suspender qualquer questionamento. Pois, curiosamente, surge no decorrer da história européia um fenômeno que transforma o meio técnico em algo novo, cujo caráter - ou cuja essência - nós ainda não compreendemos. Na Europa, e somente na Europa, vincula-se numa longa fase histórica, que começa no fim da Idade Média e estende-se até a véspera da revolução industrial, uma maneira específica de pensar - que chamamos posteriormente de científica - com a fabricação e a manipulação de artefatos e instrumentos e a empresa capitalista. 
Ciência, técnica, empresa capitalista - esta tríade faz a revolução industrial eclodir e não deixa dúvidas que estes tempos modernos distinguem-se sobremaneira dos tempos anteriores. Pois o nosso velho serrote, a pá e o martelo encontram-se agora num contexto que radicaliza, por um lado, o caráter finalístico da técnica, e que, por outro, cria meios sem finalidade definida. A máquina a vapor, por exemplo, é um desses primeiros meios que podem ser utilizados para mover serrotes ou levantar martelos, até ser equipada com rodas e, como locomotiva, sair da fábrica. A técnica moderna transcende a racionalidade de fins, que não deixa de existir, para fazer surgir meios que buscam posteriormente os seus fins. O engenheiro moderno descobre - ou desoculta - alguma coisa para perguntar depois: o que posso fazer com isso. O que posso fazer com o raios-X, a energia nuclear, o DNA ou o genoma humano? O nosso velho serrote somente sabe serrar, ele é um meio para um único fim. O nosso computador é polivalente, edita livros, dirige submarinos e admite que brinquemos com ele, admite ou exige que procuremos algo que ele possa fazer, buscamos fins porque temos um meio.

A transformação da técnica em técnica moderna se dá com esta perda do caráter finalístico da técnica, ou melhor, com a prevalência da técnica como um meio aberto. Assim, entramos no mundo do imprevisível, onde a trajetória linear está sendo substituída pelos "saltos quânticos", onde algo é necessariamente assim, mas também poderia ser diferente. A técnica moderna é altamente contingente e contamina, com essa contingência, toda a sociedade moderna.

\section{A contingência da técnica moderna}

Perceber algo como contingente significa observá-lo sob uma perspectiva diferente. Um novo olhar pode revelar a fragilidade das formas, das funções e do sentido. Algo é como é, mas também poderia ser diferente. O que sempre se apresentava de um jeito recupera agora as suas possibilidades excluídas que apontam para o ainda-não. A contingência assusta porque ela significa a expe- riência temporária da aleatoriedade e da ausência de sentido. A inclusão da técnica na percepção da contingência assusta ainda mais porque a revela como produto de escolhas ocasionais, impulsionadas por hábitos culturais, interesses econômicos ou irracionalidades de qualquer espécie. A interpretação da técnica como algo necessário quer se ver livre desta angústia, assegurando a inevitabilidade do seu desenvolvimento. Assim, para alguns, as leis da história garantem o sentido social da técnica e do seu desdobramento, mesmo se ele for negativo. Os progressistas modernistas encontram aqui solo firme, como igualmente os catastrofistas e críticos negativos que prognosticam a inevitabilidade e a necessidade da autodestruição da sociedade moderna através da técnica desenvolvida no seu bojo.

Por outro lado a percepção da técnica na sua contingência revela a existência de alternativas não realizadas. Entre o progresso e a autodestruição necessários abre-se o campo da reflexão e da comunicação social e, finalmente, a chance de um agir diferente. Começa também a busca de um desenvolvimento técnico compatível com novos valores, premeditados interculturalmente e inseridos na ação comunicativa global.

Falar da contingência da técnica, no entanto, não pode significar que o mundo está à disposição plena do homem. Muito pelo contrário, a contingência remete exatamente àquilo que Martin Heidegger chamou o segredo do Ser. As manifestações variadas do Ser fazem esquecer que o Ser destes Seres (o Ser do ente seria a expressão exegeticamente correta, mas é para a língua portuguesa uma expressão muito infeliz, torna-se um cacófato) escapa de um acesso científico e técnico pleno. A perspectiva da ciência e da técnica é sempre científica e técnica; nós não podemos observar o que não podemos observar, diria Luhmann (1990), e Heidegger (1997) introduz o conceito do desocultamento técnico para caracterizar a especificidade da técnica moderna. Neste lugar podemos somente mencionar os conceitos centrais do pensar heideggeriano sobre a técnica, são eles: a materialização, a homogeneização, a funcionalização, a polarização entre sujeito e objeto, o cálculo, a vontade do poder, a imposição, a do- 
minação, o fabricar e manusear, o consumo e a substituição, e como conceito que sintetiza tudo isso: a armação ou arrazoamento, que é a forma moderna e técnica de demandar e desafiar o Ser (Brüseke, 2000; 2001).

\section{Limites do desocultamento técnico}

Definir a técnica como uma maneira de desocultamento significa entender a essência da técnica como a verdade do relacionamento do homem com o mundo. A técnica não é mais algo exterior e exclusivamente instrumental, mas a maneira pela qual o homem se apropria e aproxima-se da natureza. Esta maneira não é algo fixo, todavia possui temporalidade e, assim, história. Na história das diversas populações, culturalmente distintas, encontramos diferentes modos de desocultamento. Estes, por sua vez, são, na sua diversidade, somente possíveis, porque o Ser permite diferentes maneiras de desocultamento. Em um certo sentido, podemos dizer que o Ser se mostra no processo do seu desocultamento sempre de um ângulo diferente. Esse aspecto do desocultamento que foge da vontade humana de dominar plenamente o seu mundo é extremamente importante. O homem não dispõe do não-velado que sempre é se mostrar e se ocultar ao mesmo tempo. Se somos incapazes de entender o que transcende o nosso horizonte, também não conseguiremos entender o retroceder do real. O desocultamento técnico moderno, sendo exclusivamente técnico, esquece este outro lado do desocultar, que é a permissão limitada, dado pelo próprio Ser, de participar no seu segredo. Desocultar o Ser significa sempre deixar algo no escuro, o Ser nunca se revela na sua plenitude.

O próprio homem, sentindo sua inferioridade, suas limitações cognitivas e sua impotência prática coloca freqüentemente taboos ante os segredos do mundo. Não olha! Não toca! Não entra! As diversas culturas humanas estão repletas de prescrições e proibições que regulam seu contato com o mundo. Este regulamento tem uma função protetora, pois afasta o homem de aventuras e descobertas ainda grandes demais para sua habilidade e seus instrumentos. Como descobrir e desocultar o mundo sem a bússola? A saída dos navios rumo ao horizonte desconhecido era há muito tempo possível mas, como voltar? O medo espalhava-se nos corações dos marinheiros quando pensavam nestas viagens sem retorno. O horizonte não ocultava um abismo que ia engolir todo o mundo que se aproximava? Se as temperaturas já aumentavam a cada dia da viagem na direção sul, ultrapassar o Equador não significava entrar diretamente no inferno. Hoje sabemos que o horizonte não engole ninguém e que o Equador não é a porta de entrada do inferno. E sabemos também que a Terra é uma bola que circula ao redor do sol. O fato de que não sabemos como provar isso quando nossos filhos nos fazem as mesmas perguntas que a Santa Inquisição fazia a Galileu, não nos inquieta, pois, já não foi provado?

A passagem da técnica, de um nível que ajudava a se situar o homem melhor no seu mundo e no seu tempo, para um nível que indica a saída do homem do seu mundo e do seu tempo, foi lenta. A tesoura do tempo da vida e do tempo do mundo (Blumenberg, 1986) abriu-se sem aviso cada vez mais. Hoje dispomos de uma técnica que tende a ultrapassar não somente o horizonte, mas também todos os limites humanos. Ela ultrapassa esses limites como se fosse o horizonte geográfico. E ela acessa o universo acompanhado por cientistas e técnicos que tratam este empreendimento como se fosse a preparação da descoberta das Américas. Podemos dizer que muitos ainda não perceberam a mudança das ferramentas e dos instrumentos de trabalho para a técnica moderna. A técnica moderna deixou, há muito, de ser simplesmente um meio. Nós pensamos tecnicamente e desocultamos o mundo tecnicamente, supondo que este mundo se deixa reduzir àquilo que denominamos matéria; supondo também um mundo objeto que esteja à espera de que o homem descubra os seus mecanismos internos, para desmontá-lo e recompô-lo ao seu gosto. Os próprios físicos, ao tornar o conceito de matéria cada vez mais complexo - conceito este que sempre transmitiu a idéia de ser algo sólido -, leva-nos a ter contato com um mundo enigmático que tínhamos aparentemente deixado para trás. 


\section{Surtos irracionalizantes}

A vontade da potência nazista, vinculada ao projeto técnico moderno é um aviso. A modernidade revela exatamente no excesso o seu potencial. Conseqüentemente, mostra estratégia militar americana do containment, seja do nacional-socialismo, seja do comunismo ou do terrorismo, que as próprias elites modernas não confiam nem por um centavo na trajetória linear e progressista desta modernidade. Chamar a autoconsciência contemporânea do potencial autodestrutivo de nossa época de crítica ou reflexiva (Giddens, 1991) só pode ser um eufemismo. Do mesmo modo o apelo à confiança dos leigos nos peritos de sistemas técnicos altamente complexos camufla que a modernidade técnica está à deriva da contingência que ela mesma evocou. O conceito de risco (Beck, 1986) adotado pela teoria social sinaliza que a sociedade moderna incorporou a consciência da sua instabilidade. Os sentimentos de ambivalência (Baumann, 1995) provocados por ela correspondem à bifurcação cuja passagem moldará a próxima época histórica.

A análise de Beck prende-se exclusivamente aos riscos que provêm do culto das forças do real. Nesta perspectiva, a sua crítica à modernidade já possui algo clássico, pois se volta contra a razão instrumental e seus efeitos desestabilizantes sobre a sociedade e o meio ambiente. O próprio conceito de modernização reflexiva define que o objeto da reflexão da modernização é ela mesma. Concordamos com a utilidade desta proposta por sua capacidade de pensar uma outra modernidade, evitando, desta maneira, a construção do artifício conceitual da pós-modernidade, mas alertamos para a restrição implícita da argumentação de Beck. Esta restrição refere-se ao esquecimento dos dois outros riscos, ou melhor, perigos, que provêm, como Loparic mostra, do culto das forças do bem e do culto das forças originárias (Loparic, 1994). A linguagem filosófica deste alerta oculta algo de relevância prática extraordinária. As grandes catástrofes do século XX, o século mais sangrento na história da humanidade, estão intimamente ligadas tanto com a sobrevalorização das forças do bem como das forças originárias. A pri- meira e a segunda guerra mundiais tiraram toda a sua força da modernidade técnica das sociedades contemporâneas, e sua mobilização totalitária ganhou força tanto de ideais nobres como de necessidades arcaicas. O nacional-socialismo, com a sua relação pré-lógica com o solo e o sangue, seu culto à comunidade dos soldados, dos camponeses e dos operários é o maior exemplo disso. Mas também o culto das forças do bem fez as suas vítimas. A cumplicidade intelectual de grandes cientistas do Ocidente e do Oriente com o regime soviético - nos anos de 1920, 1930 e 1940, tão inescrupuloso quanto seu adversário nacional-socialista - explica-se pela adesão à sua autolegitimação classista-universalizante. Esta, por sua vez, consistiu basicamente no argumento que a causa nobre, a libertação dos operários e dos camponeses das restrições historicamente impostas, justificava temporariamente a injustiça, a desigualdade e a ditadura (Courtois, 1997).

Os espantosos surtos irracionalizantes no século XX somente aproximam-se de uma compreensão analítica quando começamos a entender que a modernidade é na sua raiz técnica. A técnica, por sua vez, contribui em função de seu caráter contingente para uma destituição da predominância da racionalidade de fins, tão característica da fase histórica na qual surgiu o capitalismo, por uma racionalidade contingente. Essa racionalidade desoculta científica e tecnicamente o Ser, sem dispor de um fim que daria direção ou identificaria limites. Sem direção e limites a modernidade técnica desenvolve-se racionalmente, sem que haja uma proteção contra oscilações irracionalizantes que castigam cada vez mais seu percurso.

\section{A indiferença valorativa da modernidade técnica}

A inclusão dos projetos nacional-socialista e comunista no conceito da modernidade técnica aumenta a inteligibilidade do vazio valorativo, para não dizer niilista, desta modernidade. Ela, entendida como essencialmente técnica, nos faz compreender melhor os fenômenos contingentes e irracionais gerados em seu seio. Não surpreende que as ditaduras desenvolvimentistas na África, 
na Ásia e na América Latina não tivessem nenhum problema com a adoção da modernidade técnica, pois ela é indiferente à sua interpretação política. $\mathrm{O}$ alto potencial transformador que a modernidade historicamente mostrou é técnico e não provém do projeto iluminista com seu simpático catálogo dos direitos humanos; também não é um projeto comunicativo que varre o globo há três séculos.

Com a técnica moderna o homem aproximase, sem proteção e experiência, tanto dos extremos do mundo material e energético, como está hoje cercado com meios a busca dos seus fins. Por causa do enfraquecimento da importância da racionalidade de fins corre o homem moderno o perigo de perder um dos últimos parâmetros que ainda o sustentava. $\mathrm{O}$ mundo administrado e manipulado, na visão de Horkheimer e Adorno, ou na perspectiva de Max Weber, a racionalização crescente, parecem dar lugar a uma estranha decomposição da unidade do mundo. Na modernidade técnica separa-se, então, a razão da história global (Richter, 1992).

\section{Terror técnico}

O atentado ao World Trade Center no dia 11 de setembro de 2001 faz cair por terra a armação da modernidade técnica com meios técnicos (e não discursivos) sem mostrar alternativas. Obviamente, a reação da modernidade técnica ameaçada é técnica; para ela, o problema do terrorismo (técnico) apresenta-se como um problema de controle. Por isso, ela buscará cada vez mais controlar os elementos que complicam o seu funcionamento. Podemos até dizer que, em vez de destruir ou questionar a modernidade técnica, o terrorismo acelera sua emergência. O ato terrorista do dia 11 de setembro coloca o funcionamento do mundo técnico na ordem do dia, mas não o seu fundamento.

Parece que estes três conceitos marcam todo o espectro do dilema do mundo de hoje: controle, consenso, valor. O mundo ocidental tenta reconquistar o controle sobre uma sociedade que se desregula cada vez mais com facilidade; nesta tentativa ela colide com seu próprio princípio fundante, que é a liberdade individual e a contingên- cia de todos os procedimentos científicos e técnicos. O controle não pode admitir que algo possa ser diferente do que o que aparece nos roteiros da segurança máxima. Pois o controle, na medida em que ele se torna basicamente um problema técnico, muda seu caráter sociológico. Não é mais uma ideologia totalitária, como a ideologia soviética ou fascista, que deu seu sentido específico ao terror. Ele deve contribuir, nestas sociedades fechadas, para a coesão social. Também se diluem na contemporaneidade as formas simples e diretamente sociais do controle, através dos olhares da vizinhança, dos hábitos comunitários enraizados ou de qualquer outra tradição, pois o controle técnico necessita de um input que não é técnico.

São mobilizados, então, meios discursivos para gerar consenso acerca das necessidades do controle, processo que dominou a política exterior dos Estados Unidos nas semanas posteriores ao atentado. Ora, o consenso, exatamente por causa de sua fundamentação comunicativa, depende de múltiplos fatores políticos, sociais, históricos, culturais, psicológicos e circunstanciais que, apesar de ter de ser levados em consideração para gerar o controle, dificultam enormemente o seu processo de implantação. Criar consenso sob pressão governamental leva, mais cedo ou mais tarde, a uma necessidade de se reduzir a complexidade do processo comunicativo: eis aí o próximo passo, que resulta na divisão do mundo em aliados e adversários. "Quem não está conosco, está com os terroristas" resume, também para o leigo em razão comunicativa, a situação.

\section{A quebra do consenso da sociedade de risco}

Antigamente, era o indivíduo dissidente quem ameaçava o coletivo, o sistema e o Estado. Hoje estamos diante de um novo fator. Sob as condições da modernidade técnica, o indivíduo ou uma pequena rede humana torna-se capaz de detonar os riscos técnicos da sociedade moderna. Difícil viver em paz quando um bando de delinqüentes quebra o consenso da sociedade de risco até então, e este consenso era: nós temos de re- 
duzir os riscos ou até eliminá-los. Os dissidentes da modernidade técnica, sejam eles serial killers, seitas japonesas, talebans, ou outros que ainda vão surgir, renunciaram a este consenso. Os terroristas de Nova York conduziram os aviões em seu poder na direção de um risco de extrema improbabilidade até então: chocar-se contra uma edificação alta de um centro urbano. A sociedade de risco, este conceito de Ulrich Beck ultrapassado e radicalizado pelos atentados do dia 11 de setembro, torna-se uma sociedade de extrema vulnerabilidade quando alguns decidem, em vez de evitar, evocar a catástrofe.

Mas além do problema do controle e do consenso, mencionamos também o valor como conceito-chave nesta época. O que isto quer dizer? Que a técnica é incapaz de gerar ou fundamentar valor. Se um possível consenso se refere somente ao funcionamento ou se a segurança da técnica absorve qualquer manifestação não-técnica, ela torna funcional, de uma certa maneira, o consenso para seus próprios fins. Mas o consenso também não fundamenta o valor. Ele pode ser simpático ou necessário (como atualmente é necessário um consenso antiterror) mas não é capaz de apontar para os fundamentos do valor além da esfera da comunicação. O curioso problema que o mundo globalizado tem com os diversos fundamentalismos resulta dessa dificuldade. É curioso porque a modernidade técnica é a expressão mais radical de um mundo dessacralizado e racionalizado. O fundamentalismo - seja qual for a sua bandeira -, de forma sintomática, aponta para a necessidade do fundamento. Nos gritos histéricos dos fundamentalistas ouve-se o clamor pelo valor fundamentado. E, de fato, o valor precisa de um fundamento para conseguir fornecer critérios de possíveis consensos.

Acontece que a modernidade técnica está tão longe do fundamento como nunca esteve antes. Somente se aproximando das perguntas essenciais, somente integrando sua dinâmica técnica num universo maior do que aquele que aparece na experimentação científica ou nas construções e artefatos, poderíamos nos superar para buscar uma saída. A contingência, que não é uma invenção humana, também nos diz que isso é possível.

\section{BIBLIOGRAFIA}

BAUMAN, Zygmunt. (1995), Modernidade e ambivalência. Rio de Janeiro, Jorge Zahar.

BECK, Ulrich. (1986), Die Risikogesellschaft [A sociedade de risco]. Frankfurt, Suhrkamp.

BLUMENBERG, Hans. (1986), Lebenszeit und Weltzeit [Tempo da vida e tempo do mun$d o]$. Frankfurt, Suhrkamp.

BRÜSEKE, Franz Josef. (1996) A lógica da decadência. Belém, CEJUP.

. (1998), "A crítica da técnica moderna". Revista Estudos - Sociedade e Agricultura, abr. 10: 5-56, Rio de Janeiro, CPDA.

(1999), "A técnica moderna e o retorno do sagrado". Tempo Social (Revista de Sociologia da USP), maio, II (1), : 209-230.

(2000), "A técnica e os riscos da modernidade, segundo Heidegger", in Selene Herculano et al. (orgs.), Qualidade de vida e riscos ambientais, Niterói, EDUFF.

(2001), A técnica e os riscos da modernidade. Florianópolis, EDUFSC.

(2002), A mistica da resistência. Florianópolis, EDUFSC, no prelo.

COURTOIS, Stéphane. (1997 [1999]), O livro negro do comunismo: crimes, terror e repressão. Rio de Janeiro, Bertrand Brasil.

EMMERICH, Wolfgang; Wege, Carl. (1995), Der Technikdiskurs in der Hitler-Stalin-Ära [O discurso sobre a técnica na época HitlerStalin]. Stuttgart, Weimar, Metzler.

FREYER, Hans. (1960 [1996]), "Über das Dominantwerden technischer Kategorien in der Lebenswelt der industriellen Gesellschaft" ["Sobre a tendência de dominação das categorias técnicas no mundo da vida da sociedade industrial"], in Peter Fischer (org.), Technikphilosophie, Leipzig, Reclam.

GIDDENS, Anthony. (1991), As conseqüências da modernidade. São Paulo, Editora da Unesp. 
HEIDEGGER, Martin. (1997), "A questão da técnica" ["Die Frage nach der Technik"]. Cadernos de Tradução, 2: 40-93, São Paulo, USP, Departamento de Filosofia.

LEIS, Héctor Ricardo. (1999), A modernidade insustentável. Petrópolis, Editora Vozes.

LOPARIC, Zeljko. (1994), "A ética da finitude", in Benedito Nunes (org.), A crise do pensamento, Belém, Editora Universitária.

LUHMANN, Niklas; BUSEN, Frederick D. \& Baecker, Dirk. (1990), Unbeobachtbare Welt [O mundo não observável]. Bielefeld, Haux.

MUMFORD, Lewis. (1966 [1977]), Mythos der Maschine [O mito da máquina]. Frankfurt, Fischer.

RICHTER, Emanuel. (1992), Der Zerfall der Welteinheit. Vernunft und Globalisierung in der Moderne [A decomposição da unidade do mundo: razão e globalização na modernidade]. Frankfurt/New York, Campus.

SOUZA, Jesse. (2000), A modernização seletiva. Brasília, Editora UNB.

TOURAINE, Alain. (1992), Crítica da modernidade. Lisboa, Instituto Piaget.

WEBER, Max. (1981), A ética protestante e o espírito do capitalismo. São Paulo, Pioneira.

WITTGENSTEIN, Ludwig. (1918 [1994]), Tractatus logico-philosophicus. São Paulo, Edusp. 


\section{A MODERNIDADE TÉCNICA}

Franz Josef Brüseke

\section{Palavras-chave}

Modernidade; Técnica; Contingência; Nacional-socialismo; Comunismo; Democracia

O fato de que a modernidade, como época histórica, nasce com a ciência e técnica moderna, mostra hoje toda sua virulência. Podemos até dizer que essa modernidade é tão penetrada pela "técnica" que ela pode ser denominada e caracterizada como "modernidade técnica". Propomos este conceito para evidenciar sua essência e falamos sobre a emergência desta modernidade para evocar, por um lado, seu advento processual e histórico e, por outro, seu alto grau de instabilidade e imprevisibilidade. A técnica contribui, em função de seu caráter contingente, para uma destituição da predominância da racionalidade de fins, tão característica da fase histórica na qual surgiu o capitalismo, por uma racionalidade contingente. Essa racionalidade desoculta científica e tecnicamente o Ser, sem dispor de um fim que daria direção ou identificaria limites. Sem direção e limites a modernidade técnica desenvolve-se racionalmente, sem que haja uma proteção contra oscilações irracionalizantes que castigam cada vez mais seu percurso. Apresentamos o nacional-socialismo alemão, o comunismo russo e a democracia americana como três tipos ideais da modernidade técnica. Um olhar comparativo na direção da tríade modernizante do século XX demonstra tanto a indiferença valorativa da modernidade técnica, quanto nos faz compreender melhor os fenômenos contingentes e irracionais gerados no seu bojo.

\section{TECHNICAL MODERNITY}

Franz Josef Brüseke

\section{Keywords}

Modernity; Technique; Contingency; National-socialism; Communism; Democracy

The fact that modernity, as a historical event, emerges with modern science and technique, shows all its virulence today. It is even possible to say that this modernity is so embedded in "technique" that it can be named and characterized as a "technical modernity." This article proposes that such a concept can be used to reveal the essence and to discuss the emergency of this modernity in order to evoke, on one hand, its processual and historical event and, on the other hand, its highly unstable and unpredictable degree. Giving its contingent character, the technique contributes to a deprivation of a rationality of ends predominance, something characteristic of the historical phase in which the capitalism appeared within a contingent rationality. This rationality reveals the Being scientifically and technically but without revealing an end to be reached that could give direction or even identify its limits. With no direction or limits, the technical modernity is developed rationally, lacking protection against irrational oscillations that progressively punish its route. The article presents the German national-socialism, the Russian communism and the American democracy as three ideal types of the technical modernity. A comparative glance in the direction of this modernizing triad of the XXth century shows the indifference for values for the technical modernity at the same time that promotes the understanding of the contingent and irrational phenomena generated in this process.

\section{LA MODERNITÉ TECHNIQUE}

Franz Josef Brüseke

\section{Mots-clés}

Modernité; Technique; Contingence; National-socialisme; Communisme; Démocratie

Le fait que la modernité, en tant qu'époque historique, soit née avec la science et la technique moderne, affiche, actuellement, toute sa virulence. Nous pouvons même dire que cette modernité est de telle façon pénétrée par la "technique", qu'elle peut être dénommée et caractérisé en tant que "modernité technique". Nous proposons ce concept pour mettre en évidence son essence, et nous parlons de l'émergence de cette modernité pour évoquer, d'un côté, son apparition processuelle et historique et, d'un autre, son haut degré d'instabilité et d'imprévisibilité. La technique contribue, en fonction de son caractère contingent, à une destitution de la prédominance de la rationalité de buts, si caractéristique de la phase historique dans laquelle le capitalisme est apparu, par une rationalité contingente. Cette rationalité dévoile scientifiquement et techniquement l'Être, sans disposer d'un but qui indiquerait une direction ou identifierait des limites. Sans direction et sans limites, la modernité technique se développe rationnellement, sans qu'il y ait de protection contre les oscillations irrationnelles qui s'opposent de plus en plus à son parcours. Nous présentons le nationalsocialisme allemand, le communisme russe et la démocratie américaine en tant que trois genres d'idéaux de la modernité technique. Un regard comparatif dans la direction de la triade modernisante du $\mathrm{XX}^{\mathrm{e}}$ siècle démontre l'indifférence de valeurs de la modernité technique, et nous permet de mieux comprendre les phénomènes contingents et irrationnels conçus en son sein. 